\title{
Survival of the riskiest?
}

David L. Sills

Risk. By John Adams. UCL Press: 1995. Pp. 228. £35, \$65 (hbk); £12.95, \$21.95

(pbk). Distributed in the United States by Taylor and Francis.

THE torrent of books on risk shows no sign of abating, and for a very good reason; the topic is of considerable concern to all who live in modern, technologically based societies. There is abundant evidence from scientific reports and the daily press that technology has its dark side. But most of us are unwilling to withdraw to presumably safer low-technology environments, and the achievements of medical science have (so I believe) made us more interested in survival than any of our forebears ever were. We are all risk takers, and we hope that the emerging speciality of risk analysis will contribute to our safety. It is little wonder that risk analysis is described in this book as "the world's largest industry". Included as working in the industry are people employed in home safety, fire protection, casualty services, recreational safety, occupational safety, safety on the road, pure food and drug regulation, and the armed forces. The list goes on and on.

John Adams, a reader in geography at University College London, has published extensively in the field of road safety, the subject of his previous book Risk and Freedom. He now attempts to generalize the topic of road safety to a theory of risk in general. He provides useful comments on the work of such risk analysts as the US political scientist Aaron Wildavsky (Searching for Safety) and the German sociologist Ulrich Beck (Risk Society). He discusses a wide variety of risks and devotes a whole chapter to the greenhouse effect (he is sceptical about the evidence produced so far) but he is at his best when he writes about what he knows best: road safety.

Nearly one quarter of Risk is devoted to the analysis of the effectiveness of seatbelts and other automobile safety issues, for Adams has a great deal to say about them. His basic thesis is an extremely counterintuitive one: the mandatory use of seat-belts does not save lives among users and increases deaths among pedestrians.

The seat-belt debate seems to have been more heated in the United Kingdom than in the United States. In any event, Adams reports that both countries were "among the last of the world's highly motorized countries to implement seat belt laws". The largely unchallenged claim was made in the British parliament in 1979 that 1,000 lives and 10,000 injuries a year would be saved if seat-belts were used. In the United States, the claim was made in 1978 that 89,000 lives would be saved over the next ten years if seat-belts were used.
Adams explains these (to him, unjustified) claims by a widespread lack of awareness of "risk compensation and the possibility that there might be a behavioural response to the compulsory wearing of seat-belts". According to his interpretation, people wearing seat-belts feel more secure and so drive faster than they normally would. As evidence, he presents data from 17 countries containing more than 80 per cent of the world's car popula-

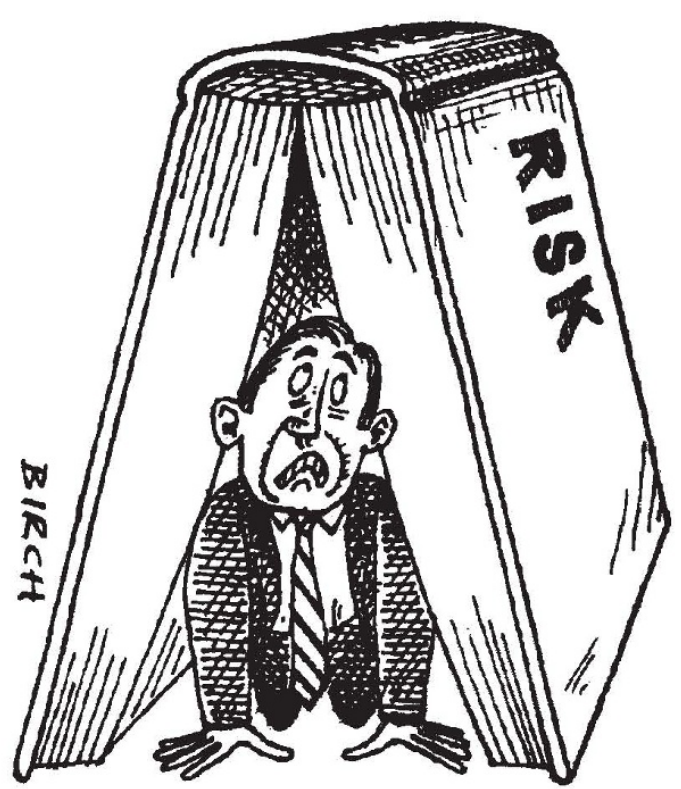

tion. During the early 1970 s, roadaccident deaths declined steeply in all countries (presumably because by then most cars were fitted with seat-belts) but declined most precipitously in countries without compulsory seat-belt legislation (presumably because in countries in which the wearing of seat-belts was compulsory, more people actually used their seat-belts and compensated by driving faster).

Adams's broad conclusion about seatbelt legislation is that because of risk compensation, many people drive faster while using seat-belts and accordingly increase their chances of a fatal accident; furthermore, because there are more speeding cars on the road, more pedestrians and cyclists are killed.

Here are examples of two common phenomena. First, legislation intended for one social purpose (saving the lives of motorists) has the unanticipated consequence of harming others (pedestrians and cyclists). Second, it is the educated and thoughtful people (drivers who drive carefully while seat-belted) who benefit the most from social legislation (wearing a seat-beit reduces one's chances of being killed, if in a crash, by 41 per cent); it is the uneducated and the reckless who are harmed. The rich get richer and the poor get poorer.

An interesting parallel is a very successful US television show for children, 'Sesame Street'. It was started many years ago to level the playing field for children from culturally deprived homes. Audience research has shown, however, that because culturally favoured children are more likely than others to watch 'Sesame Street', the programme has actually widened the gap. Individual children, culturally deprived or not, of course benefit from watching it.

Adams's focus throughout the book on statistics based on the risk perception of individuals as well as on the consequences of accidents for individuals - leads him to neglect one of the most promising avenues of research into risk: examining the formal properties of accidents themselves. To his credit, he describes the cultural, psychological and political contexts of risk behaviour, but he seems unaware of normal accident theory, as presented in Charles Perrow's Normal Accidents (Basic Books, 1984), which I reviewed in Nature (309, 185; 1984).

Perrow's normal accident theory concentrates on the properties of technological systems themselves rather than on the errors made by owners, designers and operators. Perrow thus seeks a more basic explanation for accidents than operator error or faulty equipment; he does this by analysing the ways in which the components of a system are interrelated. If Perrow were studying deaths from automobile accidents, he would undoubtedly want to examine each accident in a sample of accidents, looking for ways in which the driver, the automobile, other automobiles, speed, the road and other conditions are related. The outcome of wearing or not wearing a seat-belt would certainly be one situation examined.

It is unfortunate that Adams seems to be unaware of Perrow's pessimistic theory of normal accidents, but even without the inclusion of this perspective, his own pessimistic analysis is stimulating and rewarding. Both scholars would agree with the proposition that risk is endemic to a modern technological society, and living so as to limit one's exposure to danger is the best strategy for the thoughtful individual to follow. Fasten your seat-belt and drive slowly.

David L. Sills is at 14 Crockett Street, Rowayton, Connecticut 06853, USA. 